\title{
Direct expansion gas cooling technology applied to the E-ELT M4 adaptive mirror
}

\author{
Pescoller Dietrich ${ }^{\mathrm{a}}$, Biasi Roberto ${ }^{\mathrm{a}}$, Tintori Matteo ${ }^{\mathrm{b}}$, Manetti Mauro ${ }^{\mathrm{a}}$, Mantegazza Marco ${ }^{\mathrm{b}}$, \\ Merler Alberto ${ }^{\text {a }}$
}

${ }^{a}$ Microgate Srl, via Stradivari, 4 - 39100 Bolzano-Bozen (BZ) - Italy

${ }^{\mathrm{b}}$ A.D.S. International Srl, via Roma, 87 - 23868 Valmadrera (LC) - Italy

\begin{abstract}
The E-ELT M4 adaptive mirror is based on the voice-coil contactless adaptive mirror technology, with more than 5000 actuators controlling the mirror shape. Its driving electronics is expected to dissipate about $7-8 \mathrm{~kW}$, with consequent heat generation. Considering the M4 mirror location inside the telescope optical path, it is very important to minimize the temperature difference between the system and the ambient surrounding it, to avoid the possible introduction of wavefront optical aberrations because of air convection phenomenon. Therefore, a dedicated cooling system is mandatory. Past solutions were based on glycol liquid cooling, which proved to be adequate in terms of performances. However, the given M4 complexity and modularity requirements, together with the constant research of improved system reliability, suggested moving from the actual glycol solution to a direct expansion gas cooling system [1]. The advantages of this new approach are: negligible system damages in case of cooling leakage because of instantaneous gas evaporation, improved overall cooling system efficiency, which in turn allows a very low coolant flow rate, and an improvement of the cooling system performance in terms of system temperature uniformity. Cooling based on direct gas expansion technology is nowadays widely used in several industrial and civil applications. The present work shows experimental tests performed on the EELT M4 Demonstration Prototype (E-ELT M4DP), which prove that an appropriate implementation of this technology to the adaptive optics instruments can satisfy the stringent system cooling requirements and can be potentially applied to other leakage-sensitive instruments.
\end{abstract}

Keywords: E-ELT, adaptive optics, deformable mirror, gas expansion cooling system

\section{E-ELT M4 DEMONSTRATION PROTOTYPE}

The E-ELT M4 mirror represents a challenge within the deformable mirrors designed for adaptive optics. Therefore, a Demonstration Prototype was built already during the first phase of the project [2][3][4], so that several features of the system could be tested. More recently, during the advanced preliminary design phase, the same Demonstration Prototype has been completely renewed to be representative of the final unit [5], see Figure 1. This prototype is equipped with 10 electronics bricks, capable of controlling 280 actuators, 222 of which handle two slender shells simulating the segmentation of the final mirror. The bricks are electronics units, which group together some actuators mounted on a cooled aluminum plate. Each brick can carry from 28 to 36 voice coil motors. Every brick embeds all the control, communication, voice coil motor driver and supply functions needed by the adaptive mirror (see Figure 2). Every brick dissipates energy with consequent heat generation and an appropriate cooling system is mandatory. On one side, the cooling system must keep the temperature of the electronics boards of the bricks within acceptable limits, on the other side the temperature difference between the system and the ambient must be minimized to avoid the introduction of optical aberrations because of air convection. To this aim the aluminum plate of each brick is equipped with an internal machined cooling channel, where the gas can expand, removing heat from the system. All the internal cooling channels of the bricks belonging to the same system segment are connected in series through hoses and quick-connectors, as shown in Figure 3, while bricks of different segments are connected in parallel to the cooling system. The concept of the quick connectors is of primary importance because the single brick must be an easily replaceable unit to satisfy the system maintenance requirements. 


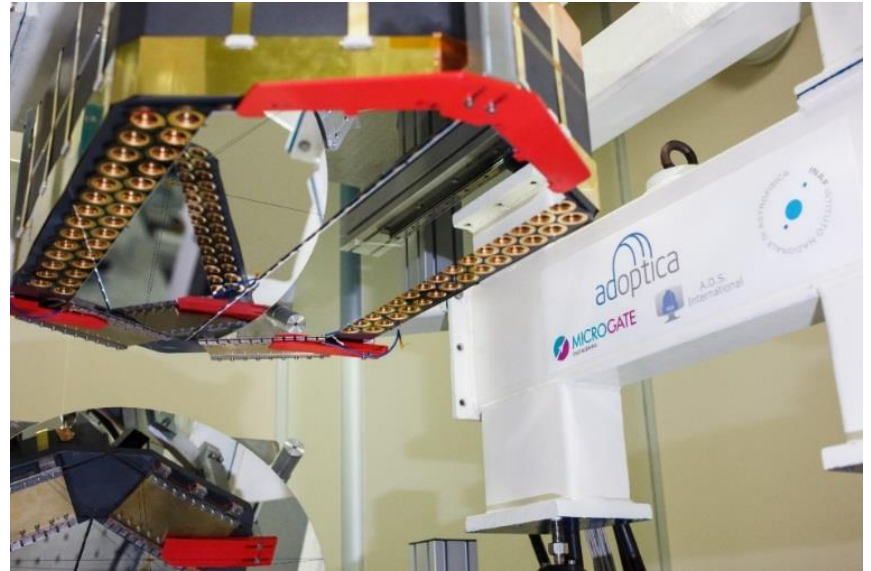

Figure 1: E-ELT M4 Demonstration prototype, shell view from bottom.

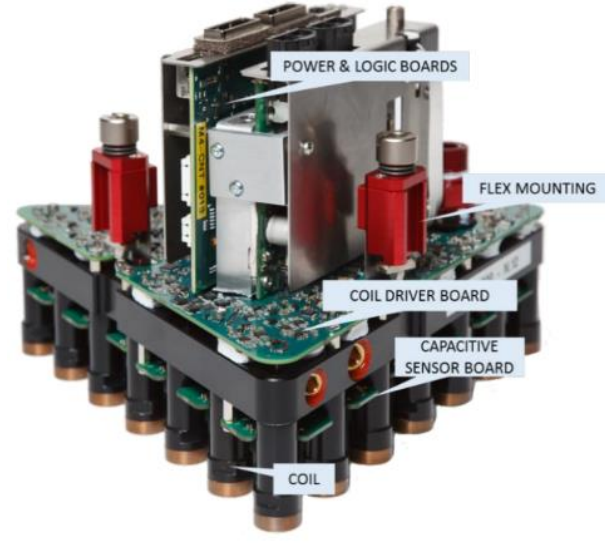

Figure 2: brick electronics unit.

\section{GAS COOLING CONTROL STRUCTURE}

The new expansion gas cooling solution requires all the typical components of a system based on refrigeration cycle: compressor, condenser, expansion valve, evaporator, pressure control valve. The refrigerant, i.e. R134a, enters the compressor in a pure gas state, after compression the fluid passes through the condenser so that a high pressure refrigerant liquid is obtained. Once reached the unit, thanks to the uplink, the refrigerant expands through expansion valves, positioned at the beginning of parallel circuits, one for each mirror segments. After expansion the flow is in a two-phase state, i.e. the fluid boils at a constant temperature while passes through the bricks of each segment, absorbing heat from the system. In this way the adaptive mirror itself becomes the evaporator. The boiling temperature of the fluid inside the evaporator is set by controlling the evaporator pressure, through a single pressure valve positioned at the evaporator outlet. The flow at the evaporator outlet is enforced to be in a gas state (superheated flow) by controlling the expansion valves placed at the inlet of each segment. At the unit outlet a manifold collects all the fluid in gas state and send it to the pressure valve and back to the compressor, through the cooling system downlink. The E-ELT M4 system requires a tight temperature control, so the compressor works in a continuous way. The fluid expansion process and the pressure inside the evaporator always require to be controlled through a feedback loop, and the system performance and robustness in terms of temperature uniformity in time and space is based on an appropriate tuning of the overall control system. The cooling control must guarantee that the adaptive mirror surface tracks the ambient temperature with an accuracy of $+0.5 /-1^{\circ} \mathrm{C}$.

The control structure of the gas cooling system hereafter described refers to the implementation actually used to cool the E-ELT M4 Demonstration Prototype. The rear side of the system is shown in Figure 3, where the cooling pipes connecting the triangular bricks of the system can be clearly seen. The cooling experimental setup is designed to test the operation of only two parallel segments, in place of the six segments foreseen for the final M4 unit. Therefore, the cooling lines are two: the first line remove heat from the E-ELT M4DP and from a dummy load (DL1), while the second line remove the heating from a second dummy load (DL2). The dummy loads are simply resistor, that power can be manually controlled to reproduce several operating conditions of the final unit segments in terms of thermal power dissipated.

The cooling system regulation is performed with four proportional-integral (PI) feedback control loops, which are summarized in Figure 4:

1. The first loop controls the pressure of the R134a at the evaporator inlet, i.e. the fluid pressure inside the uplink, where its state is liquid. The regulation is performed through a valve which can control the water flow rate inside the condenser (or alternatively the fan speed in case of air heat exchanger). This feedback loop assures that the fluid state at the evaporator inlet is always liquid within the system survival conditions, also it guarantees that the flow regulation valves operates at roughly constant pressure drop. 
2. The second loop controls the flow rate of the R134a inside each evaporator segment. There are $\mathrm{n}$ loops in parallel, two for the system here considered and six in the final E-ELT M4 unit. These loops can be approximated as decoupled, with possibly different power dissipation among segments. The flow valve aperture is commanded to guarantee that the fluid state at the evaporator outlet is completely gaseous, i.e. the temperature at the evaporator exit is higher than the critical temperature. The critical temperature Tc inside the evaporator is by definition the fluid boiling temperature at the pressure set inside the evaporator; the pressure inside the evaporator is assured by the third control loop.

3. The third loop controls the fluid pressure inside the evaporator, through a valve placed at the end of the evaporator itself. The actual configuration foresees only one pressure regulation valve, commanded by a PI controller. The required pressure sets the boiling temperature of the fluid inside the evaporator. The boiling temperature of the fluid inside the evaporator is time varying and it is determined through a strategy that minimizes the average difference between the temperature of the exposed system surfaces and the ambient temperature.

4. The last feedback loop controls the pressure at the compressor inlet by changing the compressor working frequency. This pressure assures that the fluid at the compressor inlet is always in gaseous state within all the temperature range defined by telescope survival requirements. Moreover, the adaption of the compressor frequency allows to optimize the pressure valve behavior at the evaporator outlet, avoiding as much as possible working conditions which are close to valve saturation, besides optimizing the overall system energy efficiency.

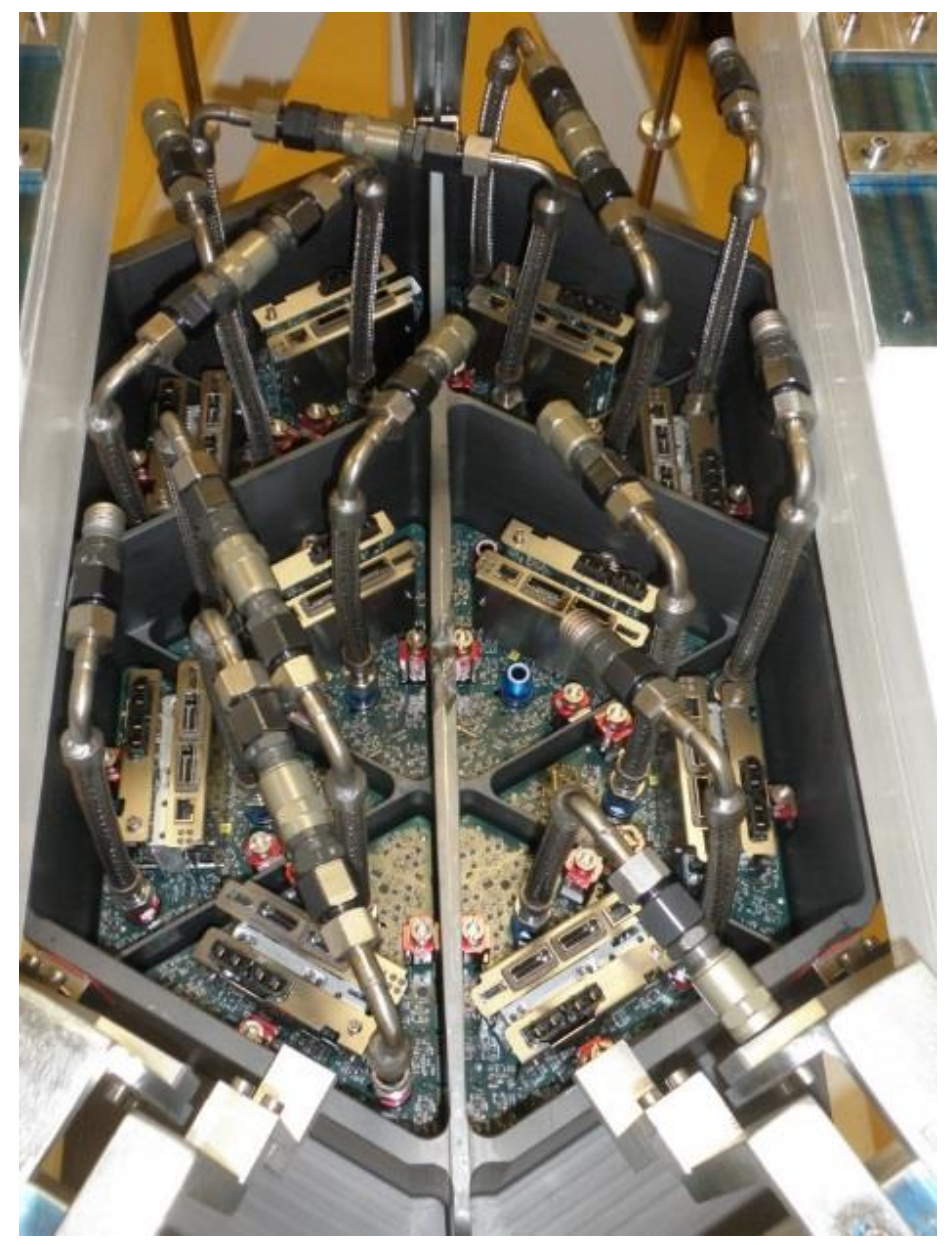

Figure 3: E-ELT MADP, rear view of the system, electronics boards mounted on bricks and cooling hoses, which connect in series all the bricks of the prototype through quick-connectors. 


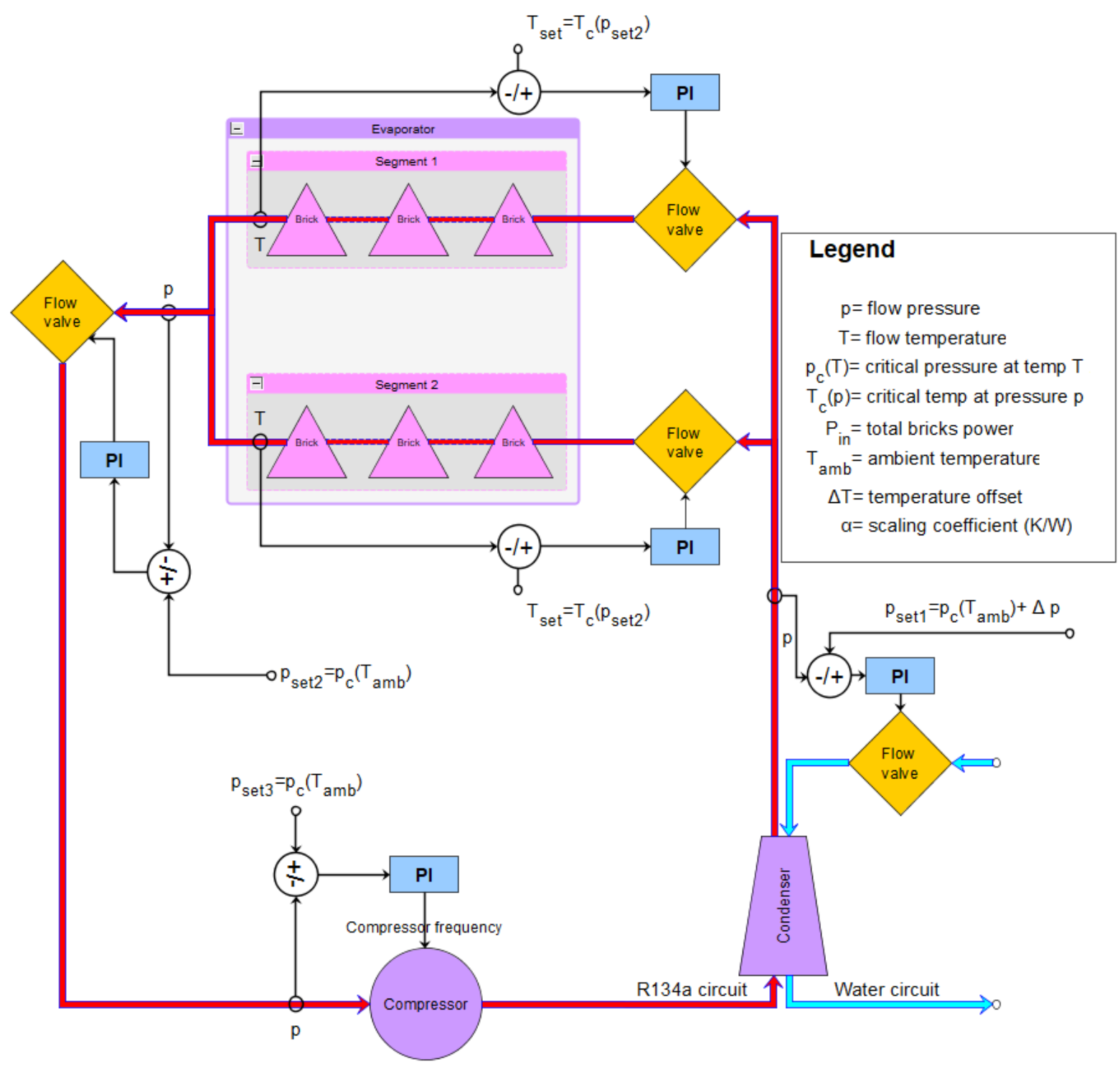

Figure 4: Sketch of the E-ELT M4 gas expansion cooling system.

\section{EXPERIMENTAL TESTS}

The E-ELT M4DP has been undergone some tests to verify the cooling system soundness and performances. In the following, it is presented a brief summary of the tests with relative results.

\subsection{Temperature tracking capability}

The aim of this test is to verify the cooling system capability to follow a temperature time history representative of the ambient temperature change during a night at the telescope location. The temperature inside the evaporator is set by controlling the pressure, i.e. the boiling temperature. Therefore, the temperature tracking error can be equivalently expressed in terms of pressure tracking error, as shown in Figure 5. The system capability to track a temperature profile inside the evaporator is reported in Figure 6, together with the temperature measurements during the test on the system dummy loads. The temperature of the dummy loads follows the temperature profile imposed inside the evaporator with an 
offset mainly driven by the thermal resistance between dummy loads and evaporator cooling pipe. Figure 7 shows the maximum temperature tracking error inside the evaporator, which is within $\pm 0.4{ }^{\circ} \mathrm{C}$.

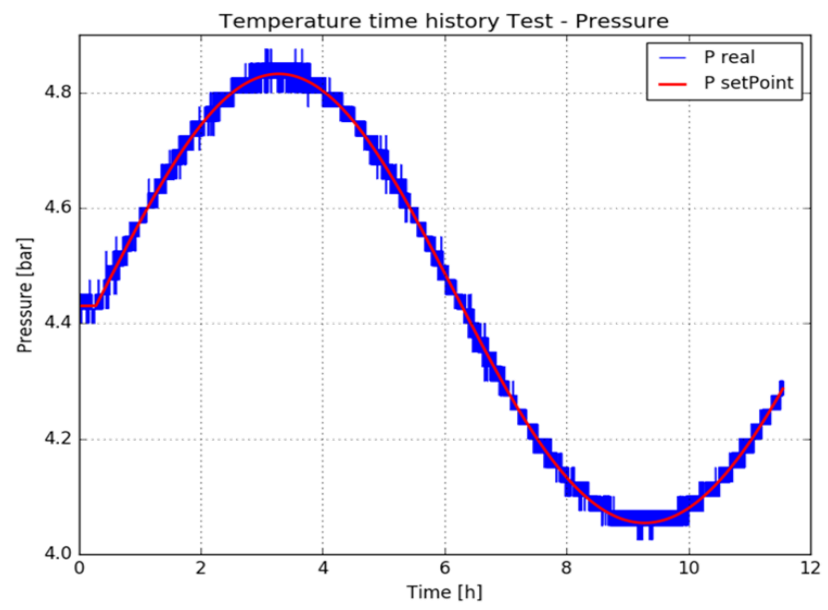

Figure 5: Boiling pressure setpoint inside the E-ELT M4DP (red line) and measured pressure (blue line).

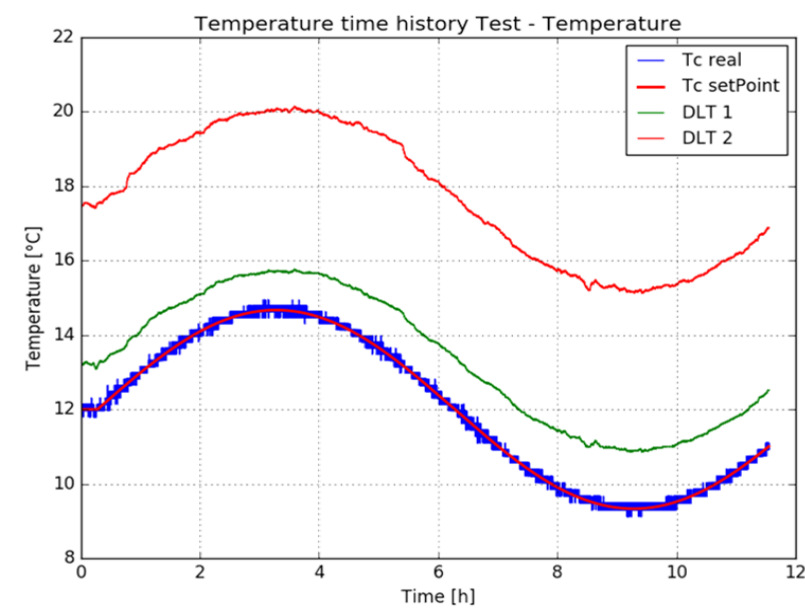

Figure 6: Several temperature profiles during the test: temperature setpoint (red line), controlled temperature inside the E-ELT M4 DP (blue line), temperature of the two dummy loads (DLT 1, DLT 2).

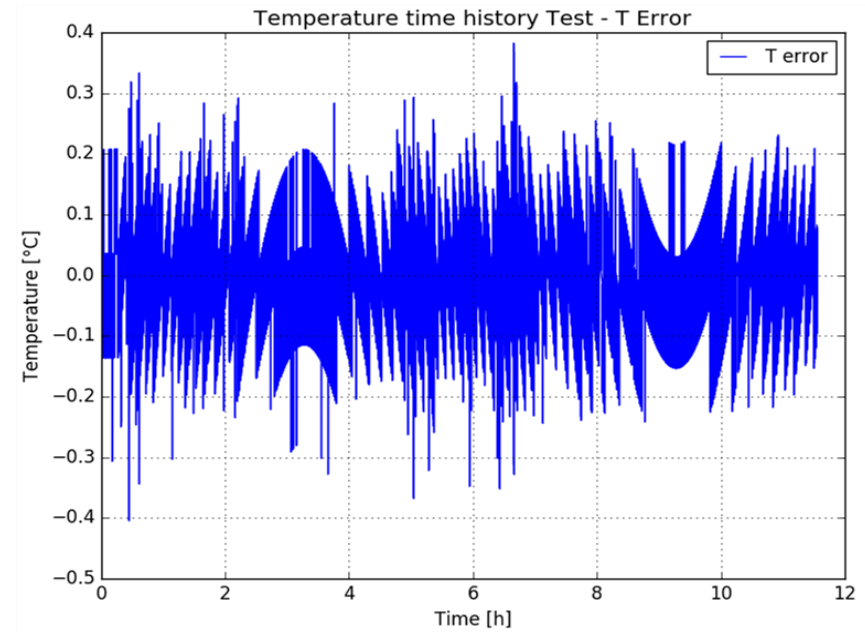

Figure 7: Tracking error of the temperature inside the evaporator.

\subsection{Compensation of an abrupt change in thermal power dissipation}

This test verifies the cooling system capability to compensate a change of power dissipation representative of different operating conditions. The power dissipation change can be simulated through the use of dummy loads, i.e. the already described high power resistors mounted on cooling plates. The power dissipated by each load can be manually regulated. Figure 8 shows the temperature variation inside the evaporator and on the dummy loads; the numbered circles mark the points where the power of dummy loads is variated, while the detail of the load variation is described in Table 1. The maximum error registered during the test is within $\pm 1{ }^{\circ} \mathrm{C}$, as shown in Figure 9, but in 20 minutes after each power change the error decreases within $\pm 0.5^{\circ} \mathrm{C}$. Figure 10 shows the pressure set point inside the evaporator and the real pressure measured; as already underlined, the pressure is the direct parameter controlled in closed loop to set the required temperature. It is worth noticing that the abrupt change of power dissipation here introduced into the system does not represent a realistic operative condition, but just a verification of the cooling system performance in a limit condition. 


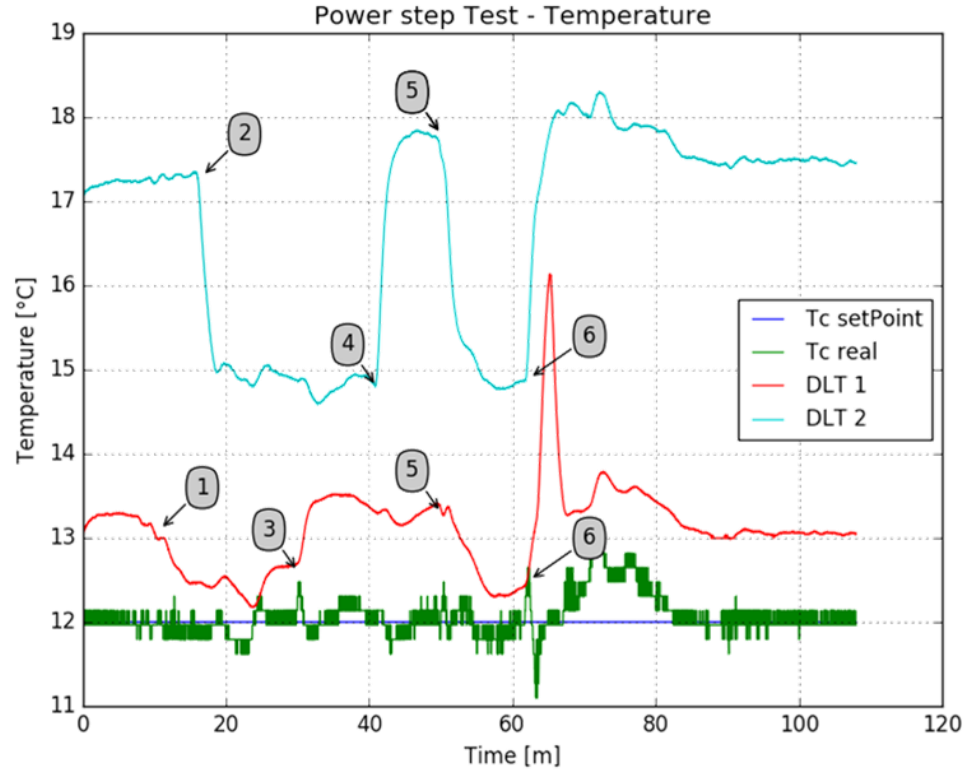

Figure 8: Temperature variation inside the evaporator and on dummy loads, as consequence of suddenly abrupt variation of the thermal power dissipated by the system.

\begin{tabular}{|l|l|}
\hline $\begin{array}{l}\text { Initial } \\
\text { lost }\end{array}$ & $\begin{array}{l}\text { Both Dummy Loads, DL1 and DL2, were } \\
\text { representative of the worst working } \\
\text { condition, i.e. 225W each one. }\end{array}$ \\
\hline $\mathbf{1}$ & $\begin{array}{l}\text { The power of Dummy Load 1, DL1, has } \\
\text { been abruptly put to 70W (No-AO). }\end{array}$ \\
\hline $\mathbf{2}$ & $\begin{array}{l}\text { The power of Dummy Load 2, DL2, has } \\
\text { been abruptly put to 70W (No-AO). }\end{array}$ \\
\hline $\mathbf{3}$ & $\begin{array}{l}\text { The power of DL1 has been put back } \\
\text { again to 225W. } \\
\text { again to 225W. }\end{array}$ \\
\hline $\mathbf{5}$ & $\begin{array}{l}\text { The power of both DL1 and DL2 have } \\
\text { been switch simultaneously to No-AO. }\end{array}$ \\
\hline $\mathbf{6}$ & $\begin{array}{l}\text { The power of both DL1 and DL2 haven } \\
\text { been switched back simultaneously to } \\
\text { Worst seeing. }\end{array}$ \\
\hline
\end{tabular}

Table 1: Step of load variation during the test.

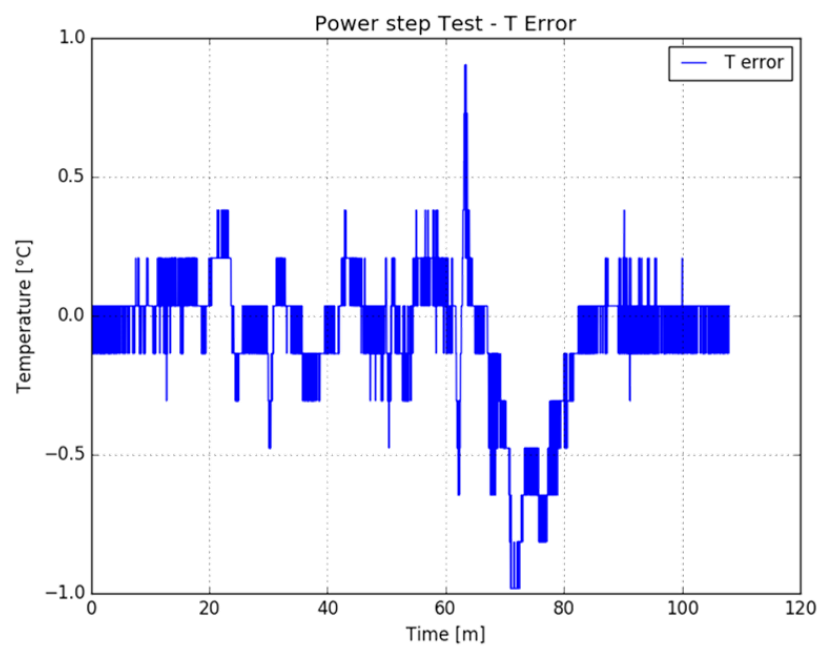

Figure 9: Temperature error inside the evaporator with respect to the temperature set point during the test.

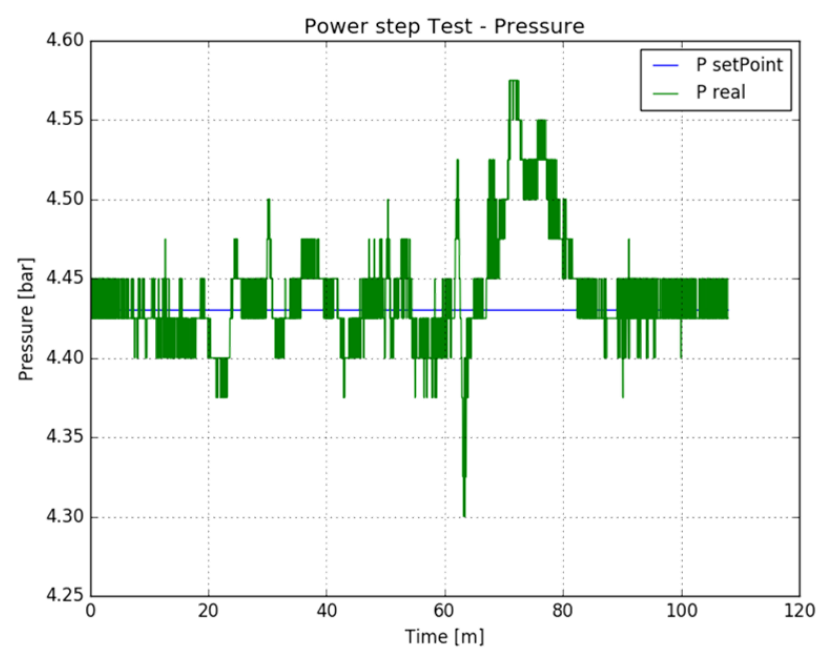

Figure 10: Pressure inside the evaporator during test and pressure set point, the pressure is the parameter directly controlled in closed loop to set the temperature.

\subsection{Elevation test}

This test is very important because allows to verify the cooling system capability to work with the system positioned at different elevation angles. The system rotation has been performed manually by rotating the dummy loads in about 3 seconds within the range $0^{\circ}-90^{\circ}$. Of course, the telescope maximum rotating velocity is much lower, so once again this test assumes very conservative hypothesis. Figure 11 and Figure 12 show the temperature variation and the evaporator 
pressure variation during the system rotation. The test results confirm the absence of a measurable impact of the rotation on the gas cooling performance and system temperature.

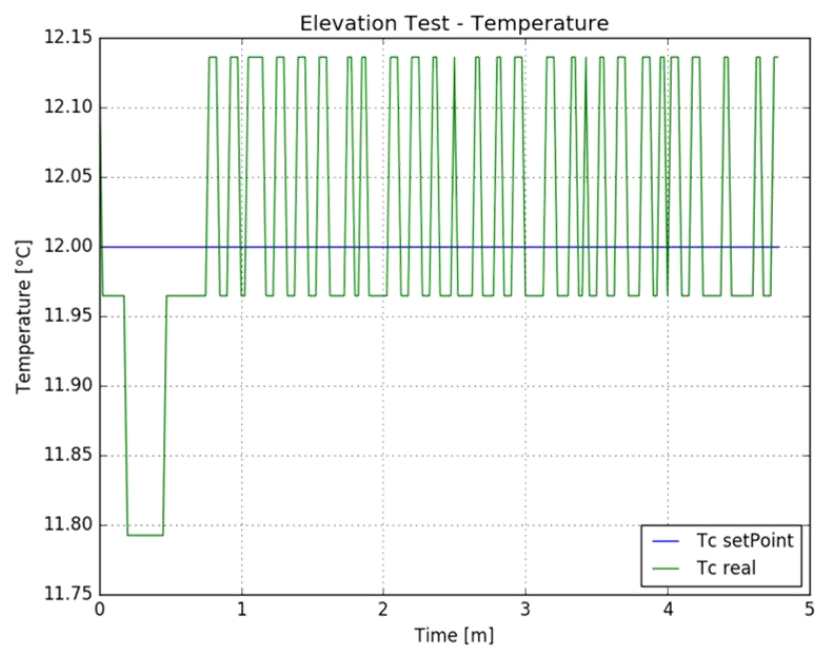

Figure 11: Temperature set point and temperature measurement inside the evaporator during the system rotation.

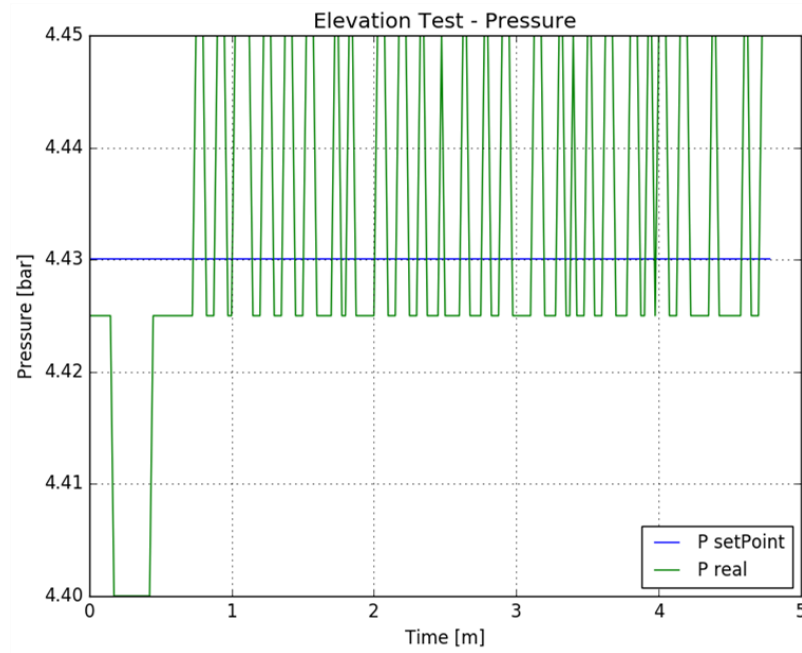

Figure 12: Pressure set point and pressure measurement inside the evaporator during system rotation.

\section{FINAL REMARKS}

All tests performed on the E-ELT M4DP confirm the soundness of the expansion gas cooling solution applied to the adaptive mirror. Both the system reliability and the risk mitigation in case of gas leakage are highly improved. Also the performance in terms of system temperature tight control in time and uniformity in space are improved with respect to the previous solution based on glycol liquid cooling.

\section{REFERENCES}

[1] Biasi, R., Manetti, M., Andrighettoni, M., Angerer, G., Pescoller, D., Patauner, C., Gallieni, D., Tintori, M., Mantegazza, M., Fumi, P., Lazzarini, P., Briguglio, R., Xompero, M., Pariani, G., Riccardi, A., Vernet, E., Pettazzi, L., Lilley, P., Cayrel, M., "E-ELT M4 adaptive unit final design and construction: a progress report", Proc. SPIE 9909, Adaptive Optics Systems V, (July 27, 2016), doi:10.1117/12.2234735

[2] Vernet, E., .Cayrel, M., Hubin, N., Biasi, R., Gallieni, D., Tintori, M., "On the way to build the M4 Unit for the E-ELT", Proc. SPIE 9148, 2014, id. 914824, doi: 10.1117/12.2056281

[3] Briguglio, R., Xompero, M., Riccardi, A., Biasi, R., Andrighettoni, M., "Optical calibration of capacitive sensors for AO: strategy and preliminary results", Proc. SPIE 8447, 2012, 84474E, doi:10.1117/12.926820

[4] Molinari, E., Tresoldi, D., Toso, G., Spanò, P., Mazzoleni, R., Riva, M., Riccardi, A., Biasi, R., Andrighettoni, M., Angerer, G., Gallieni, D., Tintori, M., Marque, G., "The optical tests for the E-ELT adaptive mirror demonstration prototype", Proc. SPIE 7736, 2010, 773632, doi:10.1117/12.857188

[5] Biasi, R., Gallieni, D., Briguglio, R., Vernet, E., Andrighettoni, M., Angerer, G., Pescoller, D., Manetti, M., Tintori, M., Mantegazza, M., Lazzarini, P., Fumi, P., Anaclerio, V., Xompero, M., Pariani, G., Riccardi, A., Cayrel, M., Dierickx, P., Hubin, N., Kornweibel, N., Pettazzi, L., "E-ELT M4 Unit updated design and prototype results", AO4ELT 4, Lake Arrowhead, 2015 